\title{
Myceliophthora thermophila M77 utilizes hydrolytic and oxidative mechanisms to deconstruct biomass
}

\author{
Hévila Brognaro dos Santos 1,3,5, Thaís Milena Souza Bezerra 4,5, José G. C. Pradella ${ }^{3}$, Priscila Delabona ${ }^{3}$, \\ Deise Lima ${ }^{3}$, Eleni Gomes ${ }^{2}$, Steve D. Hartson ${ }^{6}$, Janet Rogers ${ }^{6}$, Brian Couger ${ }^{5}$ and Rolf Prade ${ }^{5 *}$ (1)
}

\begin{abstract}
Biomass is abundant, renewable and useful for biofuel production as well as chemical priming for plastics and composites. Deconstruction of biomass by enzymes is perceived as recalcitrant while an inclusive breakdown mechanism remains to be discovered. Fungi such as Myceliophthora thermophila M77 appear to decompose natural biomass sources quite well. This work reports on this fungus fermentation property while producing cellulolytic enzymes using natural biomass substrates. Little hydrolytic activity was detected, insufficient to explain the large amount of biomass depleted in the process. Furthermore, this work makes a comprehensive account of extracellular proteins and describes how secretomes redirect their qualitative protein content based on the nature and chemistry of the nutritional source. Fungus grown on purified cellulose or on natural biomass produced secretomes constituted by: cellobiohydrolases, cellobiose dehydrogenase, $\beta$-1,3 glucanase, $\beta$-glucosidases, aldose epimerase, glyoxal oxidase, GH74 xyloglucanase, galactosidase, aldolactonase and polysaccharide monooxygenases. Fungus grown on a mixture of purified hemicellulose fractions (xylans, arabinans and arabinoxylans) produced many enzymes, some of which are listed here: xylosidase, mixed $\beta$-1,3(4) glucanase, $\beta-1,3$ glucanases, $\beta$-glucosidases, $\beta$-mannosidase, $\beta$-glucosidases, galactosidase, chitinases, polysaccharide lyase, endo $\beta-1,6$ galactanase and aldose epimerase. Secretomes produced on natural biomass displayed a comprehensive set of enzymes involved in hydrolysis and oxidation of cellulose, hemicellulose-pectin and lignin. The participation of oxidation reactions coupled to lignin decomposition in the breakdown of natural biomass may explain the discrepancy observed for cellulose decomposition in relation to natural biomass fermentation experiments.
\end{abstract}

Keywords: Myceliophthora thermophila, Biomass, Cellulose degradation, Secretome composition, Cellulose hydrolysis, Cellulose oxidation

\section{Introduction}

Lignocellulosic biomass polymers are a massive and renewable source for production of biofuels and biochemicals, because they trap about $60 \%$ of all sugars produced by plants on earth. Just as it happens in nature, man-made lignocellulosic biomass such as corn stover and sugar cane bagasse that pile up alongside bio refineries and could be broken down enzymatically

\footnotetext{
*Correspondence: prade@okstate.edu

${ }^{5}$ Department of Microbiology and Molecular Genetics, Oklahoma State University, Stillwater, OK 74078, USA

Full list of author information is available at the end of the article
}

(Amorim et al. 2011; Lal 2005). However, currently the cost of cellulase enzyme cocktails are the bottleneck to the economical production of these second generation biofuels (Phillips et al. 2011) mainly because enzymatic conversion of lignocellulose into sugars is a slow and recalcitrant process and cellulose is an insoluble crystalline substance (Himmel and Bayer 2009) clustered within phenolic lignin (benzene ether linkages) hindering its ability to be enzymatically processed (Lacayo et al. 2013).

For cellulase aided breakdown of cellulose to take place, a single chain must be separated from the crystalline fiber 
and fitted into an enzyme binding site where catalytic Asp or Glu residues hydrolyze through a general acid/ base mechanism the glycoside bond (Divne et al. 1994). The disconnection of the glucan chain from crystalline cellulose fibers has been proposed to be the bottleneck in enzymatic hydrolysis of cellulose (Himmel and Bayer 2009).

This recalcitrance towards the degradation of cellulose is abundantly illustrated in the repertoire of cellulose degrading enzymes produced by microorganisms that try to use this polymer as a carbon source (Segato et al. 2014). Most microorganisms produce at least three types of glycosidic bond breaking enzymes; cellobiohydrolases (also defined as exo glucanases and/or processive glucanases), endo glucanases and $\beta$-glucosidases. For comprehensive reviews of hydrolytic biomass breakdown refer to (Benz et al. 2013; Coutinho et al. 2009; Glass et al. 2013; Martens-Uzunova and Schaap 2009; Segato et al. 2014).

Recently oxidoreductase enzymes such as polysaccharide monooxygenases (PMO's) that directly oxidize glycoside bonds generating aldones and lactones have been discovered highlighting the role of oxidation reactions in the breakdown of biomass components (Beeson et al. 2012; Horn et al. 2012; Langston et al. 2011; Quinlan et al. 2011; Vaaje-Kolstad et al. 2010).

A direct role of cellobiose dehydrogenase on cellulose depolymerization via the oxidation of glycoside bonds aided by Fenton chemistry has been suggested (Canevascini et al. 1991; Divne et al. 1994; Henriksson et al. 2000a; Mansfield et al. 1997; Mason et al. 2003; Stahlberg et al. 1996; Westermark and Eriksson 1975; Zamocky et al. 2006). Moreover, the participation of cellobiose dehydrogenase in oxidation of other biomass components such as lignin has also been considered (Henriksson et al. 2000b; Hilden et al. 2000).

Here we report on the efficiency of biomass bioconversion by Myceliophthora thermophila M77, whereas in a traditional bioreactor, the fungus completely consumes biomass sources (sugar cane bagasse) but shows little cellulase filter paper activity, leading the research to determine global secretome composition of $M$. thermophila growing on biomass and purified biomass components (cellulose and hemicellulose). When purified cellulose was available, the fungus produced a secretome that included hydrolytic and oxidative enzymes, almost exclusively dedicated to the breakdown of cellulose and cellulose related molecules. When natural biomass was available, the fungus produced a comprehensive collection of enzymes in addition to cellobiose dehydrogenase involved in oxidation and hydrolysis of cellulose, hemicellulose-pectin and lignin.

\section{Materials and methods}

Strains, media, solutions and biomass sources

The strain used in this work M. thermophila M77 was isolated from a sugar cane bagasse pile of the northwest region of São Paulo State, Brazil and was deposited at the Fungal Genetics Stock Center FGSC\# 26436 (Moretti et al. 2012). A similar M. thermophila strain ATCC 42464 was recently sequenced by the DOE Joint Genome Institute Fungal Genomics Program (Berka et al. 2011; Kolbusz et al. 2014) and was used for DNA sequence based interpretation of LC-MS/MS data.

Myceliophthora thermophila M77 was grown on $1.8 \%$ agar petri dishes in Mandels and Sternberg salts (Mandels and Sternberg 1976) amended with $1.0 \%$ glucose and $0.1 \%$ peptone incubated at $45{ }^{\circ} \mathrm{C}$ for 7 days, or as otherwise stated. Spores were scraped off the plates with a platinum loop, suspended in $0.1 \%$ Tween 80 (SigmaAldrich, St Louis, MO, USA) and used to pre-inoculate (about $1 \times 10^{7}$ spores $/ \mathrm{mL}$ ) shaker flasks incubated at $45{ }^{\circ} \mathrm{C}, 250 \mathrm{rpm}$ for $72 \mathrm{~h}$ prior to direct transfer to a bioreactor vessel or a large-scale shaker flask experiment.

In experiments using biomass substrates and derivatives, the glucose was replaced with $1.0 \%(\mathrm{w} / \mathrm{v})$ of commercial microcrystalline cellulose (EC) (Celuflok 200 ${ }^{\mathrm{TM}}$, Celuflok Ind. Com. São Paulo, Brazil), "in natura” milled (200- $\mu \mathrm{m}$ particle size) sugar cane bagasse (SCBIN), lignin removed (sodium hydroxide extracted) and steam exploded sugar cane bagasse (SCBDL), steam exploded sugar cane bagasse only (SCBSE), wheat bran (WB), milled soybeans (SM), and fructooligosaccharides (FOS). Sugar cane bagasse sources were prepared and chemically defined as described in (Rocha et al. 2011) and milled powders washed with water and autoclaved prior to use.

\section{Shaken flask experiments}

Twenty millilitre of pre-inoculum was added to $1 \mathrm{~L}$ Erlenmeyer flasks containing $200 \mathrm{~mL}$ of Mandels and Sternberg salts, $0.1 \%$ peptone amended with $1 \%(w / v)$ SCBSE, SCBDL, WB, EC, SM, glycerol (GLY), lactose (LAC), sucrose (SUC) and FOS alone or in combinations and proportions as indicated. Incubations were made in an orbital shaker (Innova 44R Stackable Incubator Shaker, New Brunswick, NJ, USA) for up to $120 \mathrm{~h}$ at $45^{\circ} \mathrm{C}$ and $250 \mathrm{rpm}$ and samples withdrawn daily for enzyme activity and protein quantifications.

\section{Bioreactor experiments}

Bioreactor assays were performed in a lab-scale Bioflo ${ }^{\circledR} 115$ (New Brunswick, NJ, USA) with a working volume of $1.5 \mathrm{~L}$, using SCBSE, WB and sucrose as carbon sources. The pre-inoculum was $10 \%$ of the final volume. 
Cultivations were conducted in batch or pulse-fed batch mode (as indicated in Figures and Tables), the dissolved $\mathrm{O}_{2}$ concentration was $>30 \%$ of air saturation and mechanical stirring was performed with two Rushtontype impellers, in the range of $200-400 \mathrm{rpm}$. Prior to use all equipment was sterilized for $30 \mathrm{~min}$ at $121{ }^{\circ} \mathrm{C}$. Automatic $\mathrm{pH}$ control was done using a $0.4 \mathrm{M} \mathrm{HCl}$ and $\mathrm{NH}_{4} \mathrm{OH}$ aqueous solution 3:1 (v/v) and foaming was controlled as required by manual addition of sterile antifoam polypropylene glycol 2000 (Dow Chemical, São Paulo, Brazil). Samples were withdrawn under sterile conditions daily, centrifuged at $12,000 \mathrm{rpm}$ for $25 \mathrm{~min}$ at $4{ }^{\circ} \mathrm{C}$ and supernatants collected for cellulase (FPase), xylanase, $\beta$-glucosidase activity and total protein quantification.

\section{Enzymatic activity assays}

Cellulase activity was determined by the method of Ghose (1987) that measures the release of detectable reducing sugars removed from filter paper (FPase). Xylanase activity was determined by the method described by Bailey and Poutanen (1989). Both FPase and xylanase activities were performed measuring reducing sugars by the dinitrosalicylic acid (DNS) method (Miller 1959), using glucose and xylose standards as appropriate. $\beta$-glucosidase and cellobiohydrolase was measured using $p$-nitrophenol$\beta$-D-glucopyranoside (pNPG) and $p$-nitrophenol- $\beta$-Dcellobioside (pNPC) (Sigma-Aldrich, USA) as substrate, respectively (Zhang et al. 2009). Total protein content was measured in micro plates using the Bio-Rad assay reagent (Bio-Rad Laboratories, Hercules, USA), using a procedure based on the Bradford method (Bradford 1976) with bovine serum albumin as standard. One enzyme unit (IU) corresponded to the amount of product $(\mu \mathrm{mol})$ produced per minute and cellulase activity was expressed as filter paper units (FPU) calculated according to (Ghose 1987). Cellobiose dehydrogenase activity was assayed through 2,6-dichlorophenol-indophenol (DCPIP) reduction. The decrease in absorbance was measured continuously at $520 \mathrm{~nm}$ $\left(\varepsilon=6.8 \times 10^{3} \mathrm{M}^{-1} \mathrm{~cm}^{-1}\right)$ in sodium acetate buffer $(50 \mathrm{mM}$; $\mathrm{pH}$ 5) containing DCPIP $0.3 \mathrm{mM}$, sodium lactate $30 \mathrm{mM}$ and $\mathrm{NaF} 4 \mathrm{mM}$. One enzyme unit (IU) corresponded to the amount of enzyme reducing $1 \mu \mathrm{mol}$ of DCPIP per minute (Baminger et al. 1999). Laccase activity was measured continuously by the oxidation rate of $\mathrm{ABTS}^{2+}$ to $\mathrm{ABTS}^{\bullet+}$ at $420 \mathrm{~nm}\left(\varepsilon=3.6 \times 10^{4} \mathrm{M}^{-1} \mathrm{~cm}^{-1}\right)$ in acetate buffer $(50 \mathrm{mM}$; $\mathrm{pH}$ 3.5) containing ABTS (5 mM) in a final volume of $2 \mathrm{~mL}$ at $25^{\circ} \mathrm{C}$. One enzyme unit (IU) corresponded to the amount of enzyme that oxidized $1 \mu \mathrm{mol}$ of ABTS per minute (Bourbonnais et al. 1995).

\section{Enzymatic biomass hydrolysis}

Bioconversion assays were conducted in $50 \mathrm{~mL}(125 \mathrm{~mL}$ Erlenmeyer flasks) final volumes, buffered with citrate
$50 \mathrm{mM} \mathrm{pH} 5,5 \%(\mathrm{w} / \mathrm{v})$ of substrate (EC, SCBIN, SCBDL or SCBSE) and a protein load of $0.05 \mathrm{mg} / \mathrm{g}$ of glucan, incubated at $50{ }^{\circ} \mathrm{C}$ at $200 \mathrm{rpm}$. All experiments were performed in duplicates. Samples were withdrawn at 0, 6, 12,24 and $48 \mathrm{~h}$ and the glucose, gluconic acid, cellobiose, cellobionic acid, xylose, arabinose, acetic, formic and levulinic acid concentrations were quantified by HPLC Dionex Ultimate 300 system equipped with a refractive index detector (HPLC-RI) using an Aminex ${ }^{\circledR} \mathrm{HPX}-87 \mathrm{H}$ column and eluted with $5 \mathrm{mM} \mathrm{H}_{2} \mathrm{SO}_{4}$ at $0.6 \mathrm{~mL} / \mathrm{min}$. Sugars and acids in control samples containing only the respective substrate and citrate buffer $50 \mathrm{mM}$ pH 5.0 were also measured. All samples were filtered using a Millex TM $0.22 \mu \mathrm{m}$ filter prior to further analysis.

\section{Production of secretomes}

Myceliophthora thermophila M77 was grown in Erlenmeyer flasks on Mandels \& Sternberg salts, $0.1 \%$ peptone containing SCBIN (natural sugar cane bagasse, milled at $200 \mu \mathrm{m}$ particle size) as well as modified sugar cane bagasse versions such as SCBDL (delignified with sodium hydroxide), SCBSE (steam exploded), purified celluloses containing $0.5 \%$ of avicel and $0.5 \%$ carboxymethylcellulose (Sigma Aldrich, St Louis MO), purified hemicelluloses containing $0.2 \%$ of each; birchwood-, beechwood-, oat spelt-xylan, arabinan and arabinoxylan (Megazyme International, Wicklow, Ireland) and glucose (control).

Secreted proteins were collected after a $36 \mathrm{~h}$ cultivation period at $45{ }^{\circ} \mathrm{C}, 200 \mathrm{rpm}$ supernatants cleared by centrifugation $(5000 \times g)$, concentrated by ultra-filtration (10,000 MWCO, PES membrane, Vivaspin, Littleton USA), rinsed twice with $5 \mathrm{~mL}$ of sodium acetate buffer $50 \mathrm{mM} \mathrm{pH} 5$ and the proteins were separated by SDSPAGE (Weber and Osborn 1969).

\section{Secretome peptide mapping by liquid} chromatography-tandem mass spectrometry (LC-MS/MS) For secretome peptide mapping experiments two independent cultures and two protein separations through SDS-PAGE were carried out. For secretome LC-MS/MS analysis 20-30 $\mu \mathrm{g}$ of total secretome proteins were loaded onto an SDS-PAGE gel and while in Fig. 3 we show a fully resolved SDS-PAGE gel for proteomics experiments, for proteomics the SDS-PAGE was run for only about one inch into the $12 \%$ separation gel, stained with Comassie blue and the entire protein banding profile excised, processed for LC-MS/MS according to (Shevchenko et al. 1996) with modifications. Isolated gel bands were reduced with Tris (2-carboxyethyl) phosphine, alkylated by 2-Iodoacetamide, digested for $6-16 \mathrm{~h}$ with $8 \mu \mathrm{g} / \mathrm{mL}$ trypsin using ammonium bicarbonate buffer and analyzed by LC-MS/MS using LTQ-Orbitrap XL hybrid mass spectrometer (Thermo Scientific, Waltham, MA, 
USA). For this analysis, an Eksigent LC pump was used to separate peptide populations on analytical $\mathrm{C} 18$ nanocolumns, with the column effluent being sprayed directly into a New Objective Picoview ion source. Using a "Top Three" MS/MS method, the Orbitrap analyzer collected accurate $(5 \mathrm{ppm})$ scans of intact peptides for one second, at the same time as the LTQ ion trap simultaneously performed MS/MS fragmentation analysis of each of the three most abundant peptides eluting in that $1 \mathrm{~s}$ chromatographic fraction (0.8 Da mass accuracy).

The LC-MS/MS raw files were used for database Mascot (version 2.2.04, Matrix Science, London UK) searches run on a NCBI $M$. thermophila ATCC_42464 specific subset. The DNA and amino acid sequence of $M$. thermophila M77 are 98.95 and $99.45 \%$ identical to $M$. thermophila ATCC_42464, respectively. Searches were validated using Scaffold (version 4.0.7, Proteome Software Inc. Portland, OR) with a protein threshold of $5 \%$ FDR and a peptide threshold of $99 \%$. Further management of spectral data were performed on downloaded Excel files, total spectral counts (TSC) were normalized (against the total spectral count of each sample) and finally duplicates averaged (Additional file 1: Table S1). Thus, the quantitative value NTSC (normalized total spectrum counts) for a given protein component of a secretome reflects the amount of protein secreted as a direct response to the applied carbon source.

\section{Results}

\section{Bioreactors and shakers producing biomass-degrading enzymes}

Figure 1 reports a typical bioreactor experiment in which the carbon source was SCBSE (steam-exploded sugar cane bagasse). Extracellular protein and expected enzyme activities, cellulase (measured as activity on filter paper (FPU), xylanase and $\beta$-glucosidase accumulated in the medium over time reaching a peak at or around $96 \mathrm{~h}$.

Table 1 shows a series of shaking flask experiments modifying the forms of biomass and combinations with simple carbon sources such as glycerol, lactose, sucrose and glucose designed to improve enzyme production. The highest cellulase activity, as judged by the DNS assay, was observed with steam-exploded biomass (0.23 FPU/ $\mathrm{mL}$ ) while lignin extracted biomass showed lower cellulase activity $(0.10 \mathrm{FPU} / \mathrm{mL})$ and other sources such as wheat bran and purified cellulose as well as combinations thereof did not improve cellulase activity (Table 1). Thus, none of the biomass variants produced significant improvement over cellulase activity (FPU). For xylanase activity a similar picture occurs, none of the biomass derivatives improve drastically xylanase activity, however the addition of a non-repressive carbon source such as lactose (LAC), phospho-fructo-oligosacharides (FOS) or sucrose (SUC) resulted in a slight increase in xylanase activity (Table 1).

Table 2 shows a series of six bioreactor runs in which we varied $\mathrm{pH}$ and temperature, feeding schedule as well as the combination of biomass sources, designed to overcome process side effects such as the possible interference of proteases and the onset of carbon catabolite repression. With the exception of the presence of sucrose (Table 2, run \#5) that doubled the amount of cellulase, none of the other variations seemed to enhance filter paper activity.

Figure 2 describes enzymatic biomass hydrolysis into sugars and corresponding aldonic acids of various forms of sugar cane bagasse, "in natura" (SCBIN), delignified (SCBDL), steam-exploded (SCBSE) and purified cellulose (EC) by a crude enzymatic cocktail from $M$. thermophila M77 produced in a bioreactor with SCBIN as the carbon source. After $24 \mathrm{~h}$ incubation period, $6.31 \mathrm{~g} / \mathrm{L}$ of glucose and gluconic acid was produced from cellulose (EC) and 4.31, 3.16 and $1.83 \mathrm{~g} / \mathrm{L}$ from SCBIN, SCBDL and SCBSE, respectively (Fig. 2a). When the conversion potential of each carbon source was considered a $19.53 \%$ conversion was determined for SCBIN and 15.89, 8.02 and 7.63\% conversion for EC, SCBDL and SCBSE, respectively (Fig. 2b).

\section{Secretome protein composition}

The secretome (all extracellular non-anchored proteins) produced by $M$. thermophila M77 grown in various carbon sources; SCBIN, SCBDL and SCBSE as well as purified cellulose (avicel and carboxymethylcellulose) and hemicelluloses (xylans, arabinan and arabinoxylan) were determined through LC-MS/MS (Additional file 1: Table S1; Figs. 4, 5). Total extracellular proteins (secretomes) were collected, concentrated by ultra-filtration $(10 \mathrm{kDa}$ cutoff), separated by SDS-PAGE, digested with trypsin, subjected to LC-MS/MS and peptides assigned through Mascot and Scaffold to M. thermophila ATCC_42464 predicted proteins. In total, 172 proteins were unambiguously identified with positive matching of 21,766 unique peptides (4019 SCBIN, 3661 SCBDL, 4269 SCBSE 3466 celluloses and 4716 hemicelluloses). The spectral counts from two independent experiments were normalized and duplicates averaged in order to enable quantitative comparisons between samples (see Additional file 1: Table S1).

Figure 3 shows SDS-PAGE protein profiles of enzymes secreted to the medium as a response to sugar cane bagasse, purified cellulose and hemicellulose and Fig. 4 displays secretome protein abundance profiles of $M$. thermophila M77 grown with purified cellulose (left panel) and a mixture of purified hemicelluloses (right panel). All major proteins in hemicellulose were associated with hemicellulose and pectin breakdown while in cellulose all major proteins were related to cellulose hydrolysis or oxidation. 

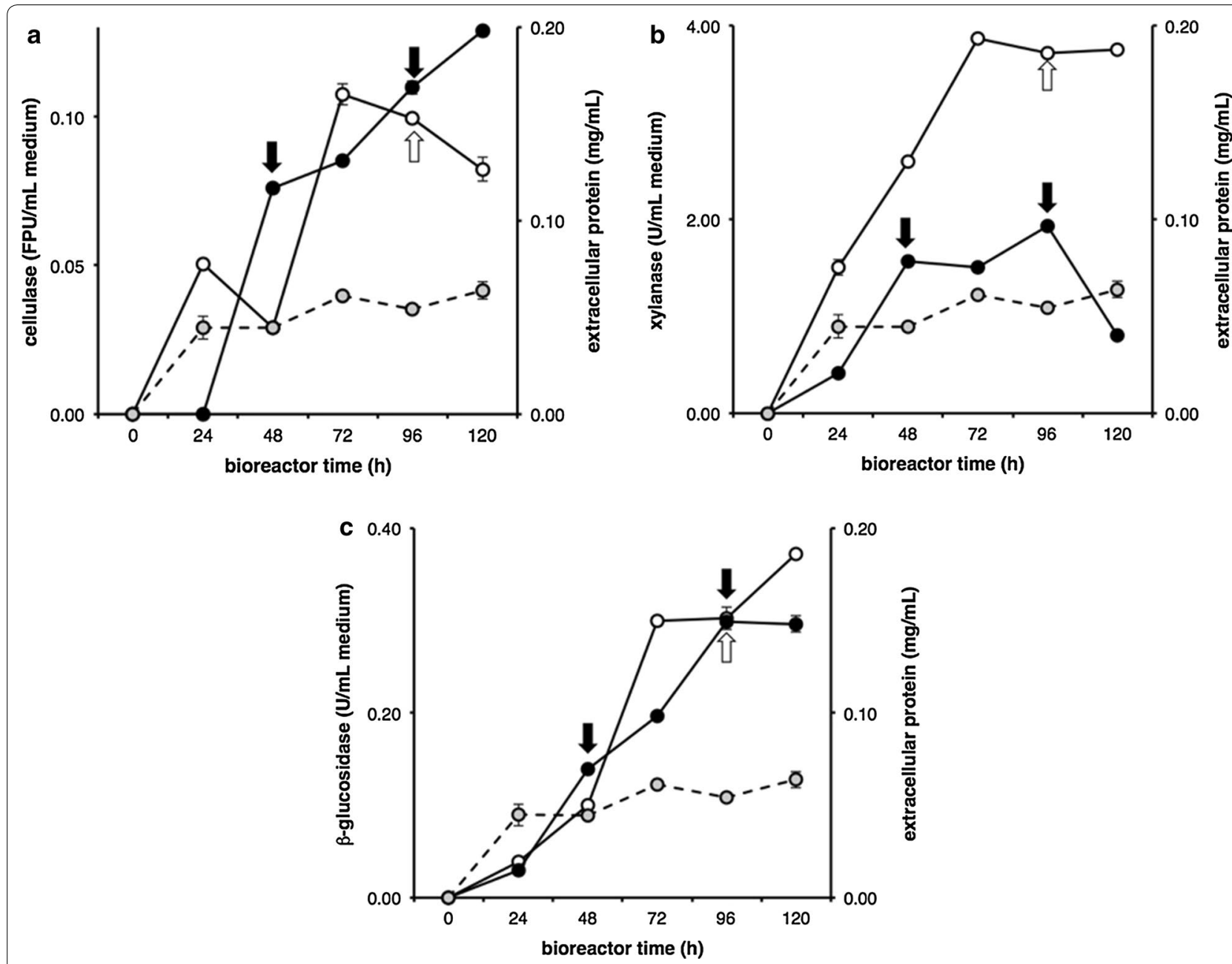

Fig. 1 Myceliophthora thermophila M77 fed-batch bioreactor with steam exploded sugar cane bagasse (SCBSE) as the carbon source. Bioreactors containing Mandels and Sternberg salts amended with $0.1 \%$ peptone and $1 \%$ steam exploded sugar cane bagasse (SCBSE) were conducted for $120 \mathrm{~h}$ at $45^{\circ} \mathrm{C}$, constant pH 5.0 and feed-pulsed with SCBSE at the indicated time points (arrows). Extracellular protein accumulation (shaded symbo/s), cellulase (a), xylanase (b) and $\beta$-glucosidase (c) activities were followed in a single feed-pulse (open symbols) and a double feed-pulse (closed symbols) regimen

In conditions where cellulose was the sole carbon source (Fig. 4, left panel) the most abundant proteins in the secretome were: GH7 cellobiohydrolase A ( 10\% of secretome), AA3 cellobiose dehydrogenase A ( $\sim 7 \%$ of secretome), GH7 cellobiohydrolase B and C ( $\sim 6$ and $\sim 4 \%$ of secretome, respectively), GH6 cellobiohydrolase A and AA3 cellobiose dehydrogenase B ( 3\% of each).

When $M$. thermophila M77 was grown in SCBIN, GH7 cellobiohydrolase A and AA3 cellobiose dehydrogenase $\mathrm{A}$ were the most abundant proteins both contributing with about $6 \%$ of the secretome each (Fig. 5), while other proteins such as GH55 $\beta$-1,3-glucanase, GH7 cellobiohydrolase B and C, GH81 endo-1,3- $\beta$ glucanase, GH74 xyloglucanase, GH43_62_32_68 arabinoxylanase, GH31 $\alpha$-xylosidase, GH3 $\beta$-glucosidase
A, catalase, hypothetical protein (MYCTH_2307339) and $\mathrm{GH} 18$ chitinase A contributed with less than 3\% of secretome, each. Polysaccharide monooxygenases (seven in total) contributed with less than 1\% each (Fig. 5). AA3 cellobiose dehydrogenase A (CdhA) on the other hand was the second most abundant protein (Fig. 4), accounting for about $6 \%$ of the secretome protein content.

We thus decided to concisely define the core cellulose secretome (Fig. 5) and further corroborate gene/protein complements. Typically, besides the classical cellobiohydrolase $\beta$-glucosidase set of proteins, cellobiose dehydrogenase, a glyoxal oxidase and an unknown GMC oxidoreductase make up the core cellulose secretome (Fig. 5). 
Table 1 Myceliophthora thermophila enzyme accumulation in shaking flask bioreactors

\begin{tabular}{|c|c|c|c|c|c|c|c|c|}
\hline & \multicolumn{2}{|l|}{ Cellulase } & \multicolumn{2}{|l|}{ Xylanase } & \multicolumn{2}{|c|}{$\beta$-glucosidase } & \multicolumn{2}{|l|}{ Protein } \\
\hline & $\mathrm{FPU} / \mathrm{mL}$ & $p(h)$ & $\mathrm{IU} / \mathrm{mL}$ & $p(h)$ & $\mathrm{IU} / \mathrm{mL}$ & $p(h)$ & $\mathrm{mg} / \mathrm{mL}$ & $p(h)$ \\
\hline SCBSE & $0.23 \pm 0.03$ & 48 & $2.90 \pm 0.06$ & 48 & $0.43 \pm 0.10$ & 72 & $0.12 \pm 0.01$ & 120 \\
\hline SCBDL & $0.10 \pm 0.01$ & 48 & $2.60 \pm 0.20$ & 72 & $0.33 \pm 0.06$ & 96 & $0.07 \pm 0.01$ & 96 \\
\hline WB & $0.12 \pm 0.02$ & 48 & $2.00 \pm 0.04$ & 24 & $1.00 \pm 0.04$ & 120 & $0.15 \pm 0.02$ & 120 \\
\hline EC & $0.10 \pm 0.01$ & 48 & $2.60 \pm 0.14$ & 72 & $0.33 \pm 0.08$ & 96 & $0.04 \pm 0.01$ & 48 \\
\hline SCBSE + WB & $0.10 \pm 0.02$ & 72 & $2.80 \pm 0.05$ & 72 & $0.55 \pm 0.05$ & 72 & $0.13 \pm 0.02$ & 96 \\
\hline SCBSE + SM & $0.13 \pm 0.02$ & 72 & $2.50 \pm 0.10$ & 48 & $0.53 \pm 0.07$ & 120 & $0.24 \pm 0.03$ & 96 \\
\hline SCBSE + SM & $0.13 \pm 0.03$ & 72 & $2.80 \pm 0.08$ & 72 & $0.42 \pm 0.05$ & 120 & $0.10 \pm 0.01$ & 120 \\
\hline $3 X S C B S E+1 X F O S$ & - & & $3.50 \pm 0.05$ & 48 & - & & $0.11 \pm 0.01$ & 24 \\
\hline $1 \mathrm{XSCBSE}+1 \mathrm{XLAC}$ & - & & $3.50 \pm 0.10$ & 72 & - & & $0.08 \pm 0.01$ & 24 \\
\hline $3 X S C B S E+1 X L A C$ & $0.19 \pm 0.02$ & 72 & $3.10 \pm 0.08$ & 72 & $0.57 \pm 0.05$ & 120 & $0.12 \pm 0.01$ & 96 \\
\hline $3 X S C B S E+1 X G L Y$ & $0.18 \pm 0.02$ & 96 & $2.80 \pm 0.05$ & 72 & $0.46 \pm 0.09$ & 120 & $0.10 \pm 0.02$ & 48 \\
\hline $3 X S C B S E+1 X S U C$ & $0.18 \pm 0.04$ & 96 & $3.30 \pm 0.12$ & 72 & $0.43 \pm 0.08$ & 120 & $0.10 \pm 0.01$ & 120 \\
\hline
\end{tabular}

SCBSE steam-exploded sugar cane bagasse; SCBDL delignified steam-exploded sugar cane bagasse; $E C$ celuflok $200^{\mathrm{Tm}}$; WB wheat bran; SM soybean mill; $G L Y$ glycerol; LAC lactose; SUC sucrose; FOS commercial phosphofructooligosacharide. Bioreactor time (h) of peak activity (p)

Table 2 Substrate influence on enzyme accumulation in bioreactors

\begin{tabular}{|c|c|c|c|c|c|c|c|c|c|c|c|c|}
\hline \multirow[t]{2}{*}{ Run } & \multicolumn{4}{|c|}{ Bioreactor conditions } & \multicolumn{2}{|l|}{ Cellulase } & \multicolumn{2}{|l|}{ Xylanase } & \multicolumn{2}{|c|}{$\beta$-glucosidase } & \multicolumn{2}{|l|}{ Protein } \\
\hline & Substrate & $\mathrm{T}\left({ }^{\circ} \mathrm{C}\right)$ & $\mathrm{pH}$ & Pulse & FPase/mL & $p(h)$ & $\mathrm{IU} / \mathrm{mL}$ & $p(h)$ & $\mathrm{IU} / \mathrm{mL}$ & $p(h)$ & $\mathrm{mg} / \mathrm{mL}$ & $p(h)$ \\
\hline$\# 1$ & SCBSE & 45 & 5 & 96 & $0.10 \pm 0.01$ & 72 & $3.88 \pm 0.12$ & 72 & $0.37 \pm 0.04$ & 120 & $0.06 \pm 0.02$ & 120 \\
\hline$\# 2$ & SCBSE & 45 & 5 & $48 / 96$ & $0.13 \pm 0.03$ & 120 & $1.93 \pm 0.13$ & 96 & $0.30 \pm 0.06$ & 96 & $0.08 \pm 0.02$ & 96 \\
\hline \#3 & SCBSE & 45 & 6 & $48 / 96$ & $0.10 \pm 0.02$ & 96 & $1.80 \pm 0.03$ & 48 & $0.48 \pm 0.03$ & 120 & $0.10 \pm 0.04$ & 96 \\
\hline$\# 4$ & SCBSE & $38-29$ & 6 & 96 & $0.18 \pm 0.03$ & 120 & $2.00 \pm 0.01$ & 120 & $0.44 \pm 0.02$ & 96 & $0.17 \pm 0.01$ & 120 \\
\hline \#5 & SCBSE + SUC & 45 & 6 & None & $0.21 \pm 0.02$ & 24 & $2.70 \pm 0.07$ & 48 & $0.72 \pm 0.01$ & 120 & $0.16 \pm 0.05$ & 24 \\
\hline$\# 6$ & WB & 45 & 6 & None & $0.06 \pm 0.01$ & 24 & $2.88 \pm 0.01$ & 24 & $1.64 \pm 0.10$ & 96 & $0.13 \pm 0.01$ & 24 \\
\hline
\end{tabular}

SCBSE steam-exploded sugar cane bagasse; WB wheat bran; SUC sucrose; $T$ temperature; (p), peak activity
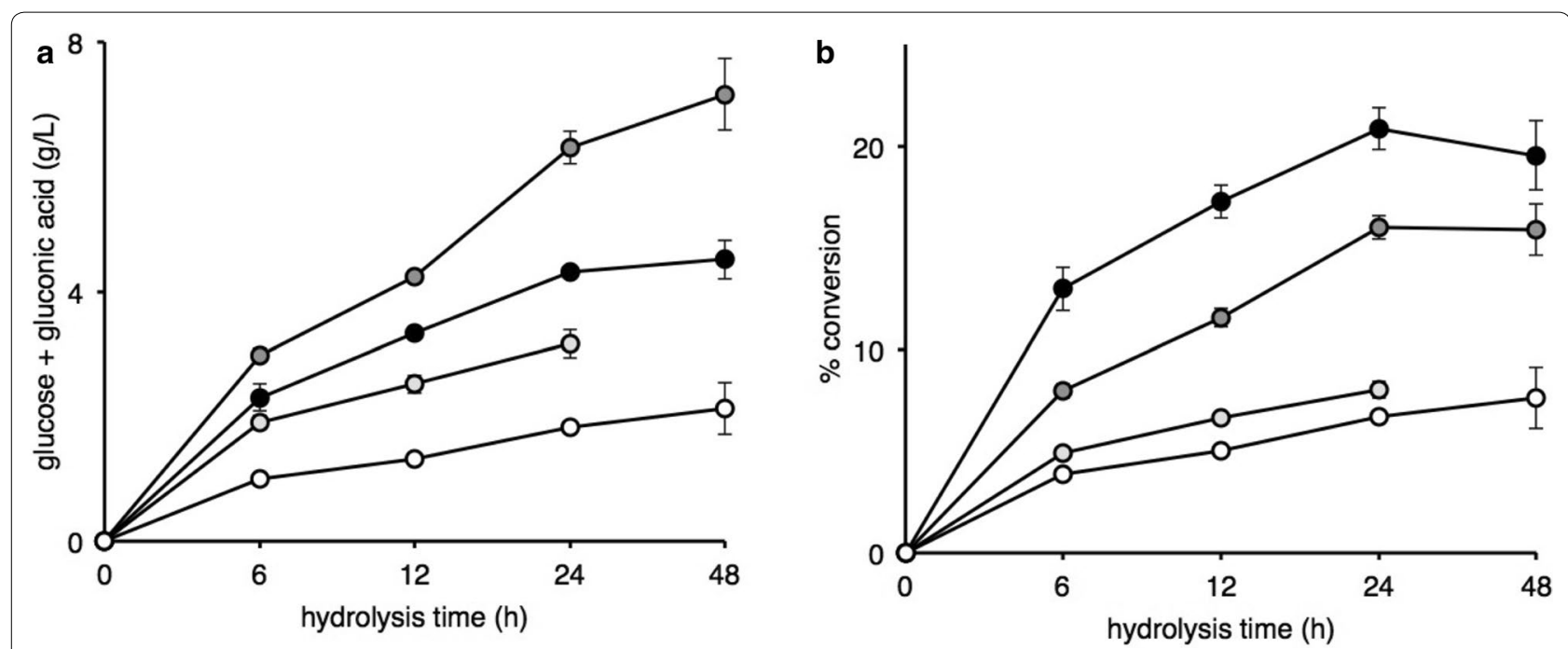

Fig. 2 Conversion of various forms of sugar cane bagasse and crystalline cellulose into glucose, gluconic acid, cellobiose and cellobionic acid by M. thermophila M77 enzymes. M. thermophila M77 secretome produced on "in natura" sugar cane bagasse was concentrated and used to hydrolyze SCBIN (closed symbols), EC (cellufloc, dark shaded symbols), SCBDL (light shaded symbols) and SCBSE $\left( \pm\right.$ ) at $50^{\circ} \mathrm{C}$. In a the release of glucose and gluconic acid is shown and in $\mathbf{b}$ the conversion percentage from total available sugars was estimated 


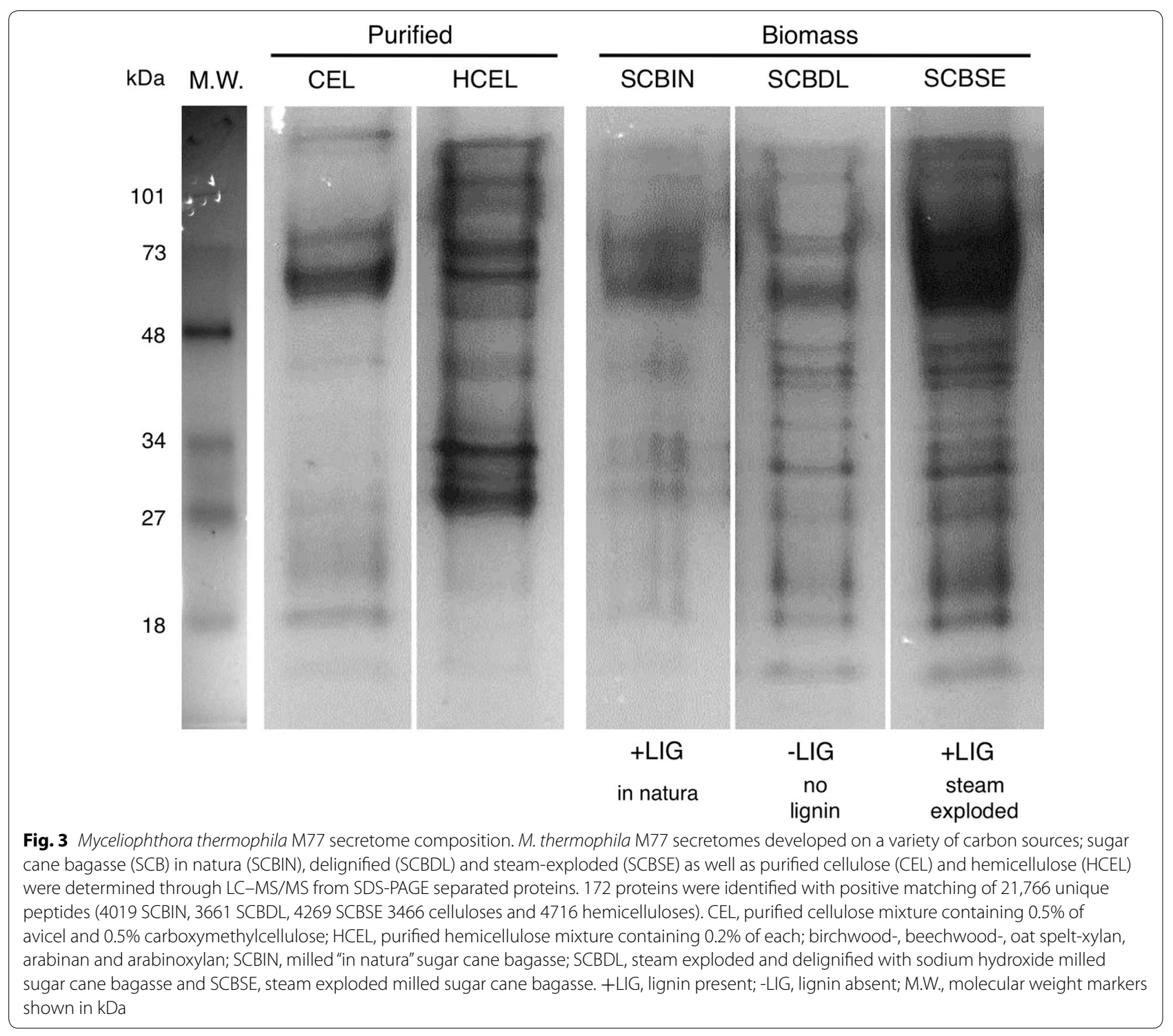

Cellulose hydrolases such as cellobiohydrolase A, B, $\mathrm{C}$ and D, GH74 xyloglucanase, GH3 $\beta$-glucosidase and GH81 endo- $\beta-1,3$ glucanase did not adjust in abundance between the three types of biomass. In addition, hemicellulose hydrolases such as GH55 $\beta$-1,3-glucanase, GH43_62_32_68 arabinoxylanase, GH7 $\alpha$-mannosidase and GH2 $\beta$-galactosidase also did not vary significantly in abundance among those three biomass substrates.

Figure 6 shows robust cellobiohydrolase, $\beta$-glucosidase and cellobiose dehydrogenase activity presence in the fluid of cultures grown on various forms of sugar cane bagasse (SCB). While cellobiohydrolase activity was present at similar levels in all biomass sources accumulating over a 4-day period and remained steady for up to 15 days cellobiose dehydrogenase accumulated for 9 days at differentiated levels in various forms of biomass and then sharply decreased and disappeared from the biomass cultures. $\beta$-glucosidase activity followed cellobiohydrolase with no difference in various biomass sources and steady accumulation over time. Laccase however poorly accumulated at the early stages of growth and then disappeared.

\section{Discussion}

Enzymatic cocktails are typically evaluated by their biomass conversion ability, which is specified by the types of enzymes involved in cellulose breakdown producing sugars (glucose and cellobiose) and their respective aldonic acids. Experiments aimed at the production of cellulases using sugar cane bagasse as the carbon source yielded 


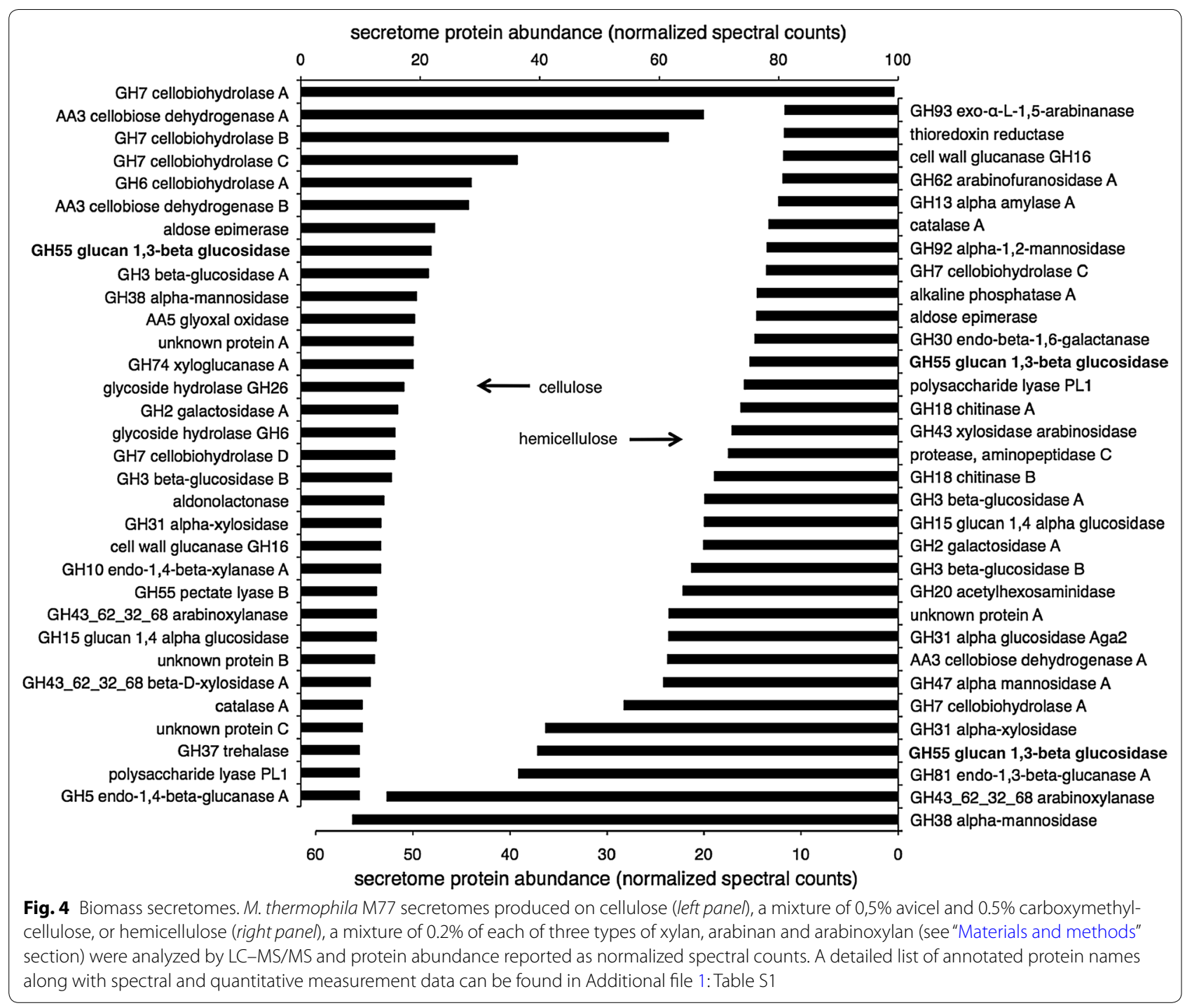

enzyme cocktails with little FPase activity even though the fungus aggressively digested the food source (Figs. 1, 2; Tables 1, 2).

We designed a series of bioreactor experiments (Table 2) to overcome process limitations. With the exception of the presence of sucrose (Table 2, run \#5) that doubled the amount of cellulase, none of the other variations seemed to enhance filter paper activity. Other fungal systems such as Aspergillus nidulans and Phanerochaete chrysosporium produce similar low levels of cellulases and xylanase when growing on solid sorghum stover (Ray et al. 2012; Saykhedkar et al. 2012).

We than designed a biomass hydrolysis experiment using the $M$. thermophila M77 enzymatic cocktail and determined the release of glucose and corresponding gluconic acid. Nevertheless, when the conversion potential of each carbon source was considered, $19.53 \%$ for
SCBIN and 15.89, 8.02 and $7.63 \%$ conversion for EC, SCBDL and SCBSE was observed, respectively (Fig. 2b). However, considering our experiment, the highest cellulase activity detected $(0.23 \mathrm{FPU} / \mathrm{mL})$ was applied on SCBIN $5 \%(\mathrm{w} / \mathrm{v})$ representing an enzyme loading of only $\sim 5 \mathrm{FPU} / \mathrm{g}$ of glucan in the hydrolysis experiment, making the observed $20 \%$ conversion rate unjustifiable, since other authors have loaded higher filter paper units (FPU) to get similar conversion rates (Adsul et al. 2005; da Silva et al. 2010; Ishihama et al. 2005; Pietrobon et al. 2011; Visser et al. 2015).

Measuring cellulose degradation by methods that only detect hydrolysis mechanisms (for instance FPase activity) may not be sufficient to evaluate the cellulose breakdown power of these enzyme mixtures because the fungus may secrete enzymes that instead of hydrolyzing cellulose, oxidize glycosidic linkages instead. 


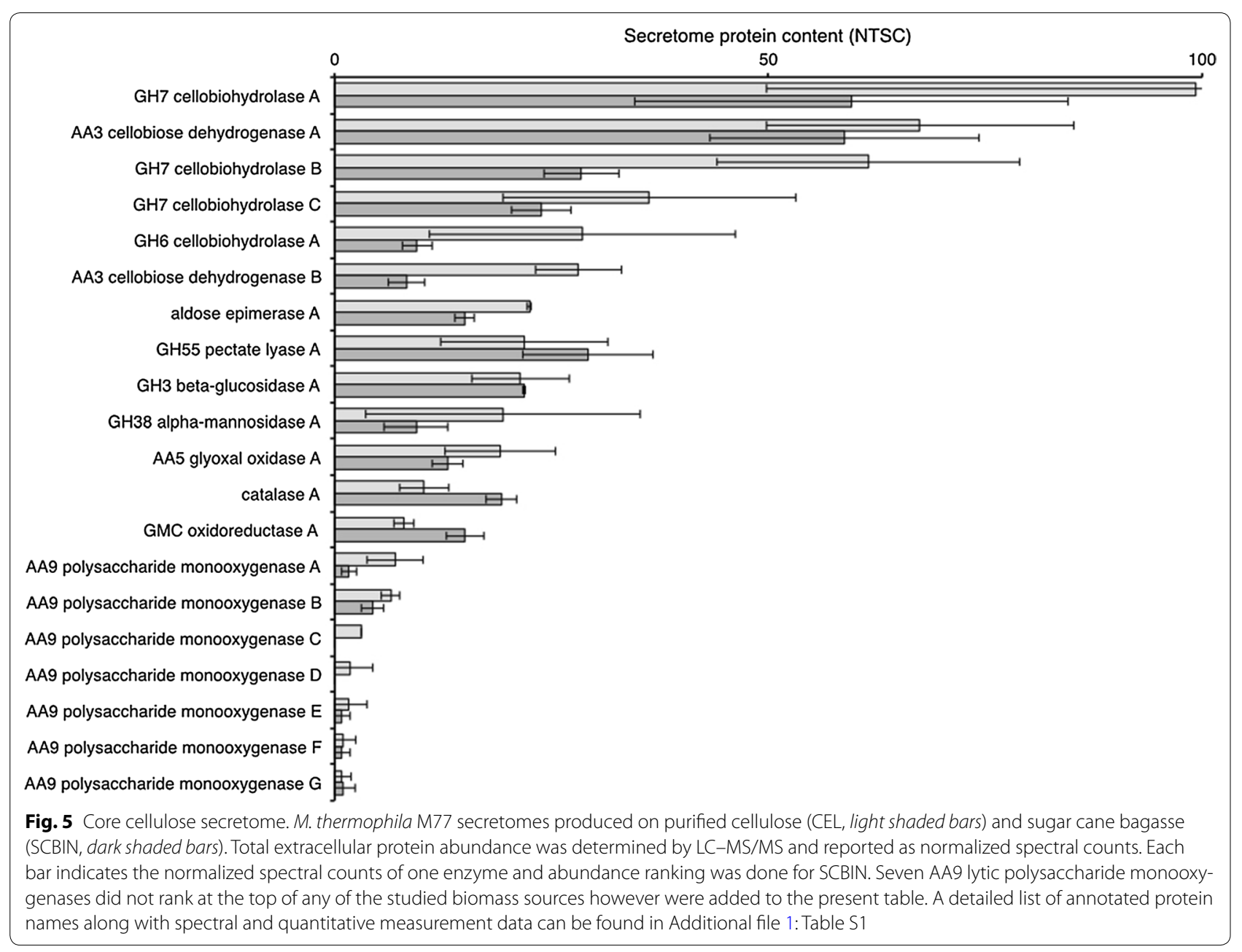

Secretome protein abundance profiles of $M$. thermophila M77 grown with purified cellulose (Fig. 4, left panel) and a mixture of purified hemicelluloses (Fig. 4, right panel) were constructed. Secretome protein profiles were substrate specific reflecting the nature of the substrate. All major proteins in hemicellulose were associated with hemicellulose and pectin breakdown while in cellulose all major proteins were related to cellulose hydrolysis or oxidation.

GH7 cellobiohydrolases (CbhA) act at the reducing end of a single cellulose chain and CbhA is the only major GH7 cellobiohydrolase that contains a cellulose-binding domain (CBM1). The presence of cellobiohydrolases devoid of cellulose binding domains, $\mathrm{CbhB}$ and $\mathrm{CbhC}$ in $M$. thermophila M77 secretomes followed similar observations made in other fungi suggesting that these CBM-devoid enzymes collaborate with CBM-bearing exo enzymes on cellulosic chains that have already been pulled apart from the crystalline fiber (Segato et al. 2012).
When grown on SCBIN, GH7 cellobiohydrolase (CbhA) and AA3 cellobiose dehydrogenase (CdhA) were the most abundant proteins both contributing with about $6 \%$ of the secretome each (Fig. 5), while other proteins contributed with less than $3 \%$ of secretome, each.

The M. thermophila M77 CdhA is a complete cellobiose dehydrogenase, a flavin-dependent dehydrogenase connected through a flexible linker to a heme-binding cytochrome and a true cellulose-binding domain (CBM1) (Tan et al. 2015). CdhA generates electrons by oxidation of cellobiose (perhaps generated by CbhA) and longer cellodextrins to 1-5- $\delta$-lactones (Westermark and Eriksson 1975). Lactones hydrolyze spontaneously in solution, or enzymatically by lactonases (also present in the secretome), to generate aldonic acids (Beeson et al. 2011). Electrons generated by the flavin-dependent dehydrogenase are shuttled via heme-binding cytochrome to the recently discovered copper dependent polysaccharide monooxygenases (PMO's) that in turn oxidize glycoside 

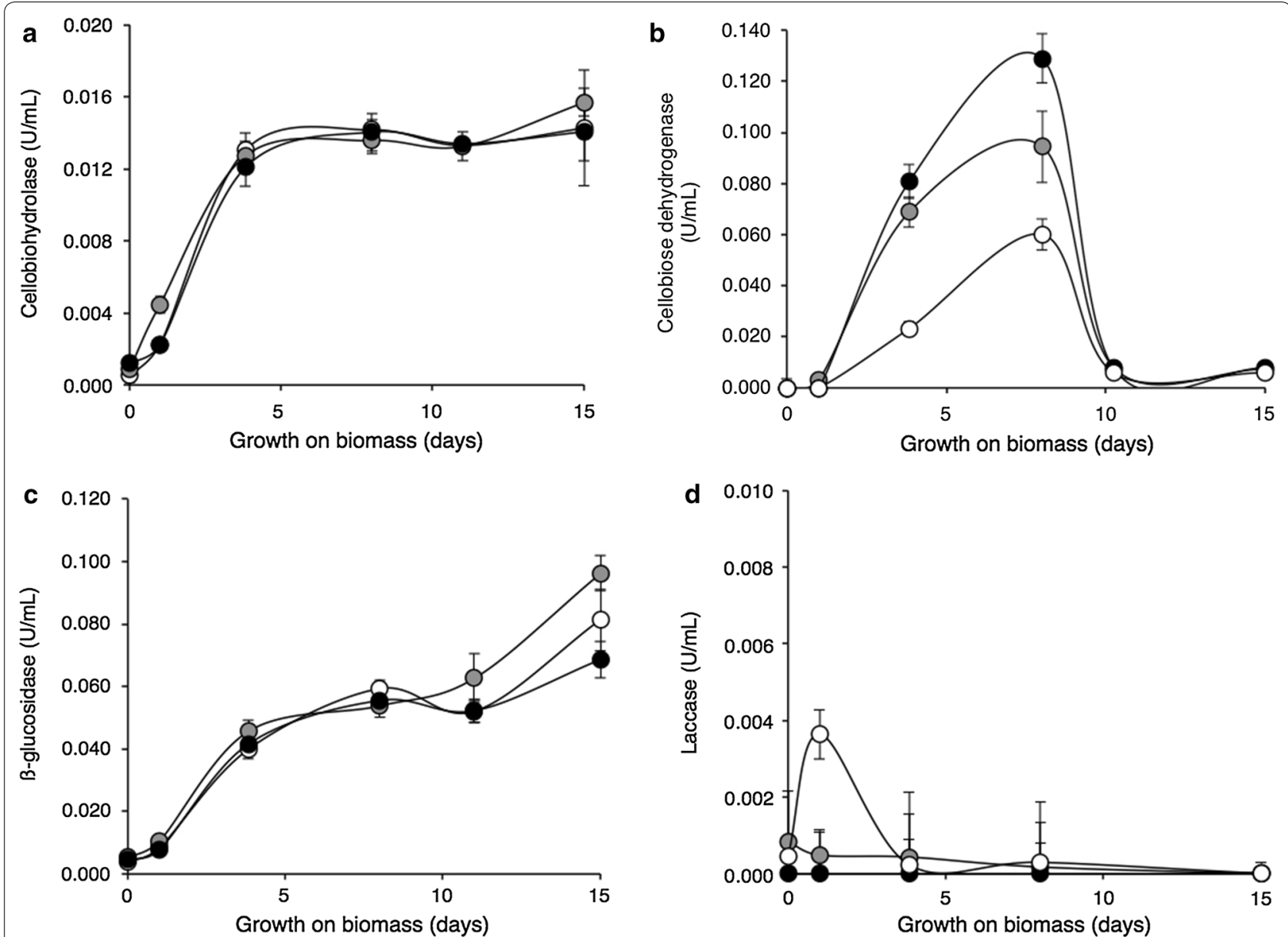

Fig. 6 Major enzyme activities on solid biomass degradation. Cellobiohydrolase (a) and $\beta$-glucosidase (c) are the major hydrolases and cellobiose dehydrogenase (b) the major oxidase secreted by M. thermophila during growth on SCBIN (closed circles) "in natura" as well as SCBDL (shaded circles) delignified and SCBSE (open circles) "steam exploded" biomass. Other oxidative enzymes laccase (d), lignin peroxidase (not shown) and Mn-peroxidase (not shown) were detected at very low levels

bonds in crystalline cellulose, hemicellulose and pectin (Beeson et al. 2011; Canevascini et al. 1991).

Remarkably, Fig. 5 shows that when the fungus grew in biomass (SCBIN) or purified cellulose (CEL) AA3 cellobiose dehydrogenase A was present in about the same concentration (about 50\%) while GH7 and GH6 cellobiohydrolases were present at higher levels in CEL. Thus, the CdhA mediated electrons could be transferred to a wide range of oxygenases (Hemsworth et al. 2013; Westermark and Eriksson 1975; Zamocky et al. 2006). Other enzymes such as GH31 $\alpha$-xylosidase, GH18 chitinase A (but not chitinase B), GMC oxidoreductase (an unknown oxidoreductase), GH43 xylosidase arabinosidase and AA5 glyoxal oxidase, followed a similar pattern, low abundance in delignified biomass and abundant in whole forms of biomass. The function of GMC oxidoreductase (GloA), glyoxal oxidase (GoxA) and GH18 chitinase even though clearly annotated by bioinformatics remain unclear and undefined.

Thus, based on the protein profile of secreted proteins and enzymatic activity detected it appears that the fungus accesses all available polymers, cellulose hemicellulose-pectin and lignin but does not produce hydrolysis products exclusively.

The participation of oxidation reactions coupled to lignin decomposition in the breakdown of cellulose chains (Beeson et al. 2012; Phillips et al. 2011), may explain the discrepancy observed between absolute FPase activity values in bioreactor experiments and the real (total) power of cellulose breakdown observed in biomass hydrolysis experiments. Furthermore, it is possible that CdhA, GloA and GoxA fail to interact and transfer electrons to cellulose, lignin and hemicellulose acceptor proteins, they generate an excess of hydrogen peroxide, 
which may directly oxidize glycosidic and phenolic bonds by a currently unknown mechanism.

Myceliophthora thermophila M77 produces specific secretomes that mirror the cell wall composition, formulate a mixed set of enzymes that in addition to hydrolyze glycoside bonds also promote coupled oxidation of cellulose and other biomass components enhancing the overall biomass degradation process. The secretome protein signature of $M$. thermophila M77 revealed cellobiose dehydrogenase (21\% of the total secretome) as the major player in cellulose oxidation partnering perhaps with oxidation proteins such as glyoxal oxidase ( $4 \%$ of the secretome content) or glucose oxidase (not very abundant). The exact function of these enzymes remains uncertain.

\section{Additional file}

Additional file 1. Comprehensive LC-MS/MS secretome analysis.

\begin{abstract}
Abbreviations
AA3: auxiliary activities 3; ABTS: 2,2'-Azino-bis(3-ethylbenzothiazoline6-sulfonic acid) diammonium salt; CBM: carbohydrate binding domain; DCPIP: 2,6-dichlorophenol-indophenol; DNS: dinitrosalicylic acid; EC: commercial microcrystalline cellulose; FDR: false discovery rate; FOS: fructoligosaccharides: FPase: filter paper cellulase activity; FPU: filter paper unit; HPLC: high performance liquid chromatography; IU: enzyme unit; GH3 7, 18, 74, 81: glycoside hydrolase family 3, 7,18, 74 and 81; GLY: glycerol; LAC: lactose; LC-MS/MS: liquid chromatography-tandem mass spectrometry; NCBI: National Center for Biotechnology Information (NIH, US); NTSC: normalized total spectral counts; PMO: polysaccharide monoxygenase; PNPC: $p$-nitrophenol- $\beta$-D-cellobioside; pNPG: $p$-nitrophenol- $\beta$-D-glucopyranoside; SCB: sugar cane bagasse; SCBDL: lignin removed (sodium hydroxide extracted) and steam exploded sugar cane bagasse; SCBIN: in natura" milled (200- $\mu$ m particle size) sugar cane bagasse; SCBSE: steam exploded sugar cane bagasse; SDS-PAGE: SDS polyacrylamide gel electrophoresis; SM: milled soybeans; SUC: sucrose; TSC: total spectral counts; WB: wheat bran.
\end{abstract}

\section{Authors' contributions}

JGCP, EG and RAP conceived and designed the study. HBS, TMSB SDH JR conducted protein analysis experiments; JGCP, PD, DL and EG conducted bioreactor experiments, $\mathrm{BC}$ acquired data, performed the bioinformatics analysis and RAP drafted the manuscript. All authors read and approved the final manuscript.

\begin{abstract}
Author details
1 Instituto de Física de São Carlos, Universidade de São Paulo, São Carlos, SP, Brazil. ${ }^{2}$ Laboratório de Microbiologia e Bioquímica Aplicada, Departamento de Biologia, IBILCE/UNESP, Rua Cristovão Colombo, 2265 Bairro Jd. Nazareth, São José do Rio Preto, SP CEP 15054-000, Brazil. ${ }^{3}$ Laboratório Nacional de Ciência e Tecnologia do Bioetanol, Rua Giuseppe Máximo Scolfaro, 10.000, Bairro Guará, Campinas, SP CEP 13083-970, Brazil. ${ }^{4}$ Laboratório de Enzimologia, Instituto de Química, UNESP, Araraquara, São Paulo, Brazil. ${ }^{5}$ Department of Microbiology and Molecular Genetics, Oklahoma State University, Stillwater, OK 74078, USA. ${ }^{6}$ Department of Biochemistry and Molecular Biology, Oklahoma State University, Stillwater, OK 74078, USA.
\end{abstract}

\section{Acknowledgements}

We value Raymond L. Huhnke's biofuels leadership with funding from the Oklahoma Bioenergy Center.

\section{Competing interests}

The authors declare that they have no competing interests.

\section{Availability of data and materials}

Strains used in this study are available from the Fungal Genetics Stock Center (Kansas City, MO). Ancillary data are submitted as Additional file 1:Table S1.

\section{Ethical approval}

This article does not contain any studies with human participants or animals performed by any of the authors.

\section{Funding}

Department of Energy, awards 06103-OKL, ZDJ-7-77608-01 and CNPq (Brazil) Science Without Borders Program awards 403090/2012-1 to RAP and 201319/2012-8 to HBS.

Received: 18 October 2016 Accepted: 27 October 2016

Published online: 02 November 2016

\section{References}

Adsul MG, Ghule JE, Shaikh H, Singh R, Bastawde KB, Gokhale DV, Varma AJ (2005) Enzymatic hydrolysis of delignified bagasse polysaccharides. Carbohydr Polym 62(1):6-10. doi:10.1016/j.carbpol.2005.07.010

Amorim HV, Lopes ML, de Castro Oliveira JV, Buckeridge MS, Goldman GH (2011) Scientific challenges of bioethanol production in Brazil. Appl Microbiol Biotechnol 91(5):1267-1275. doi:10.1007/s00253-011-3437-6 Bailey M, Poutanen K (1989) Production of xylanolytic enzymes by strains of Aspergillus. Appl Microbiol Biotechnol 30(1):5-10. doi:10.1007/bf00255989

Baminger U, Nidetzky B, Kulbe KD, Haltrich D (1999) A simple assay for measuring cellobiose dehydrogenase activity in the presence of laccase. J Microbiol Methods 35(3):253-259

Beeson WT, lavarone AT, Hausmann CD, Cate JH, Marletta MA (2011) ExtracelIular aldonolactonase from Myceliophthora thermophila. Appl Environ Microbiol 77(2):650-656. doi:10.1128/AEM.01922-10

Beeson WT, Phillips CM, Cate JH, Marletta MA (2012) Oxidative cleavage of cellulose by fungal copper-dependent polysaccharide monooxygenases. J Am Chem Soc 134(2):890-892. doi:10.1021/ja210657t

Benz JP, Chau BH, Zheng D, Bauer S, Glass NL, Somerville CR (2013) A comparative systems analysis of polysaccharide-elicited responses in Neurospora crassa reveals carbon source-specific cellular adaptations. Mol Microbiol 91(2):275-299. doi:10.1111/mmi.12459

Berka RM, Grigoriev IV, Otillar R, Salamov A, Grimwood J, Reid I, Ishmael N, John T, Darmond C, Moisan MC, Henrissat B, Coutinho PM, Lombard V, Natvig DO, Lindquist E, Schmutz J, Lucas S, Harris P, Powlowski J, Bellemare A, Taylor D, Butler G, de Vries RP, Allijn IE, van den Brink J, Ushinsky S, Storms R, Powell AJ, Paulsen IT, Elbourne LD, Baker SE, Magnuson J, Laboissiere S, Clutterbuck AJ, Martinez D, Wogulis M, de Leon AL, Rey MW, Tsang A (2011) Comparative genomic analysis of the thermophilic biomassdegrading fungi Myceliophthora thermophila and Thielavia terrestris. Nat Biotechnol 29(10):922-927. doi:10.1038/nbt.1976

Bourbonnais R, Paice MG, Reid ID, Lanthier P, Yaguchi M (1995) Lignin oxidation by laccase isozymes from Trametes versicolor and role of the mediator 2,2'- azinobis (3-ethylbenzthiazoline-6-sulfonate) in kraft lignin depolymerization. Appl Environ Microbiol 61(5):1876-1880

Bradford MM (1976) A rapid and sensitive method for the quantitation of microgram quantities of protein utilizing the principle of protein-dye binding. Anal Biochem 72(1-2):248-254. doi:10.1016/0003-2697(76)90527-3

Canevascini G, Borer P, Dreyer JL (1991) Cellobiose dehydrogenases of Sporotrichum (Chrysosporium) thermophile. Eur J Biochem 198(1):43-52

Coutinho PM, Andersen MR, Kolenova K, vanKuyk PA, Benoit I, Gruben BS, Trejo- Aguilar B, Visser H, van Solingen P, Pakula T, Seiboth B, Battaglia E, Aguilar- Osorio G, de Jong JF, Ohm RA, Aguilar M, Henrissat B, Nielsen J, Stalbrand H, de Vries RP (2009) Post-genomic insights into the plant polysaccharide degradation potential of Aspergillus nidulans and comparison to Aspergillus niger and Aspergillus oryzae. Fungal Genet Biol 46(Suppl 1):S161-S169

da Silva AS, Inoue H, Endo T, Yano S, Bon EP (2010) Milling pretreatment of sugarcane bagasse and straw for enzymatic hydrolysis and ethanol fermentation. Bioresour Technol 101(19):7402-7409. doi:10.1016/j. biortech.2010.05.008 
Divne C, Stahlberg J, Reinikainen T, Ruohonen L, Pettersson G, Knowles JK, Teeri TT, Jones TA (1994) The three-dimensional crystal structure of the catalytic core of cellobiohydrolase I from Trichoderma reesei. Science 265(5171):524-528. doi:10.1126/science.8036495

Ghose TK (1987) Measurement of cellulase activities. Pure Appl Chem 59(2):257-268

Glass NL, Schmoll M, Cate JH, Coradetti S (2013) Plant cell wall deconstruction by ascomycete fungi. Annu Rev Microbiol 67:477-498. doi:10.1146/ annurev-micro-092611-150044

Hemsworth GR, Davies GJ, Walton PH (2013) Recent insights into coppercontaining lytic polysaccharide mono-oxygenases. Curr Opin Struct Biol 23(5):660-668. doi:10.1016/j.sbi.2013.05.006

Henriksson G, Johansson G, Pettersson G (2000a) A critical review of cellobiose dehydrogenases. J Biotechnol 78(2):93-113

Henriksson G, Zhang L, Li J, Ljungquist P, Reitberger T, Pettersson G, Johansson $\mathrm{G}(2000 \mathrm{~b})$ Is cellobiose dehydrogenase from Phanerochaete chrysosporium a lignin degrading enzyme? Biochim Biophys Acta 1480(1-2):83-91

Hilden L, Johansson G, Pettersson G, Li J, Ljungquist P, Henriksson G (2000) Do the extracellular enzymes cellobiose dehydrogenase and manganese peroxidase form a pathway in lignin biodegradation? FEBS Lett 477(1-2):79-83

Himmel ME, Bayer EA (2009) Lignocellulose conversion to biofuels: current challenges, global perspectives. Curr Opin Biotechnol 20(3):316-317. doi:10.1016/j.copbio.2009.05.005

Horn SJ, Vaaje-Kolstad G, Westereng B, Eijsink VG (2012) Novel enzymes for the degradation of cellulose. Biotechnol Biofuels 5(45):1-12. doi:10.1186/1754-6834-5-45

Ishihama Y, Oda Y, Tabata T, Sato T, Nagasu T, Rappsilber J, Mann M (2005) Exponentially modified protein abundance index (emPAl) for estimation of absolute protein amount in proteomics by the number of sequenced peptides per protein. Mol Cell Proteom 4(9):1265-1272. doi:10.1074/mcp. M500061-MCP200

Kolbusz MA, Di Falco M, Ishmael N, Marqueteau S, Moisan M-C, Baptista CdS, Powlowski J, Tsang A (2014) Transcriptome and exoproteome analysis of utilization of plant-derived biomass by Myceliophthora thermophila. Fungal Genet Biol 72:10-20. doi:10.1016/j.fgb.2014.05.006

Lacayo Cl, Hwang MS, Ding SY, Thelen MP (2013) Lignin depletion enhances the digestibility of cellulose in cultured xylem cells. Plos ONE 8(7):e68266. doi:10.1371/journal.pone.0068266

Lal R (2005) World crop residues production and implications of its use as a biofuel. Environ Int 31(4):575-584. doi:10.1016/j.envint.2004.09.005

Langston JA, Shaghasi T, Abbate E, Xu F, Vlasenko E, Sweeney MD (2011) Oxidoreductive cellulose depolymerization by the enzymes cellobiose dehydrogenase and glycoside hydrolase 61. Appl Environ Microbiol 77(19):7007-7015. doi:10.1128/AEM.05815-11

Mandels M, Sternberg D (1976) Recent advances in cellulose technology. Ferment Technol 54:267-286

Mansfield SD, De Jong E, Saddler JN (1997) Cellobiose dehydrogenase, an active agent in cellulose depolymerization. Appl Environ Microbiol 63(10):3804-3809

Martens-Uzunova ES, Schaap PJ (2009) Assessment of the pectin degrading enzyme network of Aspergillus niger by functional genomics. Fungal Genet Biol 46(Suppl 1):S170-S179

Mason MG, Nicholls P, Wilson MT (2003) Rotting by radicals-the role of cellobiose oxidoreductase? Biochem Soc Trans 31(Pt 6):1335-1336

Miller GL (1959) Use of dintirosalicilic acid reagent for determination of reducing sugar. Anal Chem 31:426-428

Moretti MM, Bocchini-Martins DA, Silva RD, Rodrigues A, Sette LD, Gomes E (2012) Selection of thermophilic and thermotolerant fungi for the production of cellulases and xylanases under solidstate fermentation. Braz J Microbiol 43(3):1062-1071. doi:10.1590/ S1517-838220120003000032
Phillips CM, Beeson WT, Cate JH, Marletta MA (2011) Cellobiose dehydrogenase and a copper-dependent polysaccharide monooxygenase potentiate cellulose degradation by Neurospora crassa. ACS Chem Biol 6(12):1399-1406. doi:10.1021/cb200351y

Pietrobon VC, Monteiro RTR, Pompeu GB, Borges EPE, Lopes ML, de Amorim HV, da Cruz SH, Viegas EKD (2011) Enzymatic hydrolysis of sugarcane bagasse pretreated with acid or alkali. Braz Arch Biol Technol 54(2):229-233

Quinlan RJ, Sweeney MD, Lo Leggio L, Otten H, Poulsen JC, Johansen KS, Krogh KB, Jorgensen Cl, Tovborg M, Anthonsen A, Tryfona T, Walter CP, Dupree P, Xu F, Davies GJ, Walton PH (2011) Insights into the oxidative degradation of cellulose by a copper metalloenzyme that exploits biomass components. Proc Natl Acad Sci USA 108(37):15079-15084. doi:10.1073/pnas.1105776108

Ray A, Saykhedkar S, Ayoubi-Canaan P, Hartson SD, Prade R, Mort AJ (2012) Phanerochaete chrysosporium produces a diverse array of extracellular enzymes when grown on sorghum. Appl Microbiol Biotechnol 93(5):2075-2089. doi:10.1007/s00253-012-3907-5

Rocha GJM, Gonçalves AR, Oliveira BR, Olivares EG, Rossell CEV (2011) Steam explosion pretreatment reproduction and alkaline delignification reactions performed on a pilot scale with sugarcane bagasse for bioethanol production. Ind Crops Prod 35(1):274-279

Saykhedkar S, Ray A, Ayoubi-Canaan P, Hartson SD, Prade R, Mort AJ (2012) A time course analysis of the extracellular proteome of Aspergillus nidulans growing on sorghum stover. Biotechnol Biofuels 5(1):52. doi:10.1186/1754-6834-5-52

Segato F, Damasio AR, Goncalves TA, Murakami MT, Squina FM, Polizeli M, Mort AJ, Prade RA (2012) Two structurally discrete GH7-cellobiohydrolases compete for the same cellulosic substrate fiber. Biotechnol Biofuels 5:21. doi:10.1186/1754-6834-6835-21

Segato F, Damasio AR, de Lucas RC, Squina FM, Prade RA (2014) Genomics review of holocellulose deconstruction by aspergilli. Microbiol Mol Biol Rev 78(4):588-613. doi:10.1128/MMBR.00019-14

Shevchenko A, Wilm M, Vorm O, Mann M (1996) Mass spectrometric sequencing of proteins silver-stained polyacrylamide gels. Anal Chem 68(5):850-858

Stahlberg J, Divne C, Koivula A, Piens K, Claeyssens M, Teeri TT, Jones TA (1996) Activity studies and crystal structures of catalytically deficient mutants of cellobiohydrolase I from Trichoderma reesei. J Mol Biol 264(2):337-349

Tan TC, Kracher D, Gandini R, Sygmund C, Kittl R, Haltrich D, Hallberg BM, Ludwig R, Divne C (2015) Structural basis for cellobiose dehydrogenase action during oxidative cellulose degradation. Nat Commun 6:7542. doi:10.1038/ncomms8542

Vaaje-Kolstad G, Westereng B, Horn SJ, Liu Z, Zhai H, Sorlie M, Eijsink VG (2010) An oxidative enzyme boosting the enzymatic conversion of recalcitrant polysaccharides. Science 330(6001):219-222. doi:10.1126/science.1192231

Visser EM, Leal TF, de Almeida MN, Guimaraes VM (2015) Increased enzymatic hydrolysis of sugarcane bagasse from enzyme recycling. Biotechnol Biofuels 8(1):5. doi:10.1186/s13068-014-0185-8

Weber K, Osborn M (1969) The reliability of molecular weight determinations by dodecyl sulfate-polyacrylamide gel electrophoresis. J Biol Chem 244(16):4406-4412

Westermark U, Eriksson KE (1975) Purification and properties of cellobiose: quinone oxidoreductase from Sporotrichum pulverulentum. Acta Chem Scand B 29(4):419-424

Zamocky M, Ludwig R, Peterbauer C, Hallberg BM, Divne C, Nicholls P, Haltrich D (2006) Cellobiose dehydrogenase - a flavocytochrome from wooddegrading, phytopathogenic and saprotrophic fungi. Curr Protein Pept Sci 7(3):255-280

Zhang YHP, Hong J, Ye X (2009) Cellulase assays. Biofuels. In: Mielenz JR (ed) Methods in molecular biology, vol 581. Humana Press, New York, pp 213-231 